Research Article

\title{
Dynamic Analysis and Chaos Control of Bertrand Triopoly Based on Differentiated Products and Heterogeneous Expectations
}

\author{
Liuwei Zhao $\mathbb{i D}^{1,2}$ \\ ${ }^{1}$ School of Business, Jiangsu University of Technology, Changzhou, Jiangsu 213001, China \\ ${ }^{2}$ Computational Experiment Center for Social Science, School of Management, Jiangsu University, Zhenjiang, \\ Jiangsu 212013, China
}

Correspondence should be addressed to Liuwei Zhao; 136901672@qq.com

Received 17 April 2020; Revised 11 May 2020; Accepted 16 May 2020; Published 11 July 2020

Guest Editor: Abdul Qadeer Khan

Copyright ( $\odot 2020$ Liuwei Zhao. This is an open access article distributed under the Creative Commons Attribution License, which permits unrestricted use, distribution, and reproduction in any medium, provided the original work is properly cited.

Price competition has become a universal commercial phenomenon nowadays. This paper considers a dynamic Bertrand price game model, in which enterprises have heterogeneous expectations. By the stability theory of the dynamic behavior of the Bertrand price game model, the instability of the boundary equilibrium point and the stability condition of the internal equilibrium point are obtained. Furthermore, bifurcation diagram, basin of attraction, and critical curve are introduced to investigate the dynamic behavior of this game. Numerical analysis shows that the change of model parameters in a dynamic system has a significant impact on the stability of the system and can even lead to complex dynamic behaviors in the evolution of the entire economic system. This kind of complex dynamic behavior will cause certain damage to the stability of the whole economic system, causing the market to fall into a chaotic state, which is manifested as a kind of market disorder competition, which is very unfavorable to the stability of the economic system. Therefore, the chaotic behavior of the dynamical system is controlled by timedelay feedback control and the numerical analysis shows that the effective control of the dynamical system can be unstable behavior and the rapid recovery of the market can be stable and orderly.

\section{Introduction}

The oligopoly theory is based on two classic economic models developed by Cournot [1] and Bertrand [2]. Cournot competition is named after French economist Antoine Augustin Cournot. In 1838, Cournot argued that decisionmaking in the oligopoly market would hinge on qualities in Cournot competition, as a firm has the market power over quantities but is aware of rivals' actions. Thus, the firm can deploy its strategies based on the symmetry information it has and finally maximize its profit. In 1883, Joseph Bertrand developed a game theory model that concerns price competition in a duopoly by employing the concepts of Nash equilibrium with market prices as a strategic factor. Therefore, there is a distinct difference between Bertrand's and Cournot's economic models in terms of a firm's pricing strategy under the perfect competition, namely, pricing of marginal cost. Overall, the two economic models have made great contributions to the oligopoly markets, which are the cornerstone of the subsequent improvements and developments.

Bounded rationality and Puu's imperfect information are the two main frameworks for studying the oligopoly market. Enterprises with bounded rationality would update their own strategies based on the discrete time series and marginal benefit. Under such adjustment mechanism, enterprises do not need to have a comprehensive understanding of demand and cost functions. Instead, all they need is to decide whether they need to react with output's tiny change based on the estimated marginal benefit. The adjustment mechanism related to discrete time series has been extensively studied by numerous researchers. 
Meanwhile, some researchers believe that the decisionmaking progress of discrete time series is more down to earth than the tangible economic system, which is less likely to revise the output decision real time. Elsewhere, Puu has introduced the idea of the so-called "Puu's imperfect information" with major benefit as being close to reality. An enterprise does not need to comprehend its profit function. Instead, it only needs to understand its previous profit and prices. This provides an even more convenient method to analyze monopoly competition.

Both Naïve and Bertrand assume an enterprise uses the latest available information. Each enterprise believes its rival provides the same quantity or price and the deviation did not exist in the past period of time. Under the static background, we can conclude that the monopoly is a state of global stable balance. However, based on the rule of expectation, the marginal cost of linear demand function and constant as well as the increasing number of firms play important roles in the Bertrand duopoly. Particularly, if there are more than three firms in the market, the Bertrand-Nash balance would become instable. The paradox would be generalized $y$ changing different hypothesis, via taking different demand function $[3,4]$ and cost function $[5,6]$ into account. Thus, the research will start from the perspective of bounded rationality and imperfect information in order to transform the Bertrand duopoly from the static to dynamic forms. Furthermore, we will provide an effective chaotic control regarding the complexity of the model in order to explain how a monopoly market transforms from chaos to stability.

In an oligopoly market, each firm needs to take its and rivals' strategies into account. Thus, we see dynamics in an oligopoly competition. Furthermore, the research on linear dynamic system in oligopoly has generated the expectation rules that are more down to earth than those in Naïve expectation. In other words, we have seen expectation rules based on marginal benefit [7-9] and self-adaption [10]. In most of the literature, researchers focus on the competitive heterogeneity. Firms adopt the same set of expectation rules. However, a firm's isomerism expectation rules, such as competitive duopoly anticipated by isomers, should be closer to reality [11-13]. Recently, Fanti and Gori also analyze the dynamic model of Cournot competition [14]. Other literature also concern the analysis of competition between two firms, such as the research on three firms in oligopoly [15-17]. Currently, there is limited research on multiple heterogeneity firms in oligopoly and dynamic competition model. The study of nonlinear difference equations by Elsadany et al. believes that four heterogeneity enterprises would produce perfect substitute products in the gaming in an oligopoly. They state that the stability from Cournot-Nash equilibrium hinges on the adjustment speed from gradient firms [18-22]. Meanwhile, adaptive expectant could stabilize the process of gaming. Elsewhere, Tramontana's research $[19,23-26]$ indicates that inverse demand function of elasticity, constant marginal cost, and growing heterogeneity firms would boost the range of stable region's parameter. Andaluz and Jarne have conducted a research on different products from three heterogeneity firms. Among them, one engages in price and quantity competition based on a different linear dynamic system in oligopoly and a firm's Naïve expectation. The other two firms revise their own judgement based on a gradient criterion. The research indicates that Nash equilibrium would increase stability if the product is more independent given there are complements and substitutions for the product.

Since the beginning of the twentieth century, we have witnessed accelerated development of study on the complexity of chaos in natural science. Currently, the study has yielded abundant results. Thanks to the cross-disciplinary sturdy, the study on the complexity of chaos for social science and business management has been gradually understood. Many scholars have attempted to broaden their understanding about the complexity of chaos, control, and application of the simplest economic and management model. More recently, some researchers have begun to use dynamic game method to study realistic management questions, such as service value, channel conflict, social influence, and spillover effect [27-31].

In this paper, the research will extend the models based on the previous research made by Andaluz and Jarne [32-36]. We will attempt to construct a nonlinear dynamic Bertrand model based on the heterogeneity in expectations (namely, Naïve expectations and bounded rationality) and make use of the advanced tool of complex system theory to extend the analysis of coopetition relationship by addressing the following research questions: (i) We analyze the local stability of the Nash equilibrium under price competition but assuming a nonlinear dynamic system of a differentiated triopoly. (ii) We have constructed nonlinear dynamic Bertrand model based on differentiated products and heterogeneous expectations and analyze the Nash equilibrium's partial stability. This will be based on the hypothesis that inverse demand function and cost functions are both linear functions along with participants' bounded rationality. By employing the stability of discrete dynamical system, we analyze boundary equilibrium of three dimensions' dynamical system. In the meantime, we provide the stable parameter of interior equilibrium based on Schur-Cohn principles. (iii) The equilibrium stability of nonlinear dynamic Bertrand model would come from numerical simulation. The result of analyzing nonlinear dynamic Bertrand model's equilibrium stability via numerical simulation would discuss the parameters' impact on the dynamic system's stability and system stability. The time-delayed feedback control could effectively control the system's chaotic behavior [37, 38].

In order to solve these problems, we consider the price of the company's product as a decision variable. This paper considers both the market price function and the production cost function with knowledge absorption capabilities being linear functions, and a dynamic Bertrand price with heterogeneous expectations for participating companies is constructed. A game model and and a dynamic repetitive game model are proposed under bounded rationality. To the best of our knowledge, this article is the first to use analytical and numerical tools to consider duopoly repetitive games in dynamic Bertrand prices under conditions of limited competition. In particular, we adopt a gradient adjustment 
mechanism in economics literature to capture players' bounded rationality [16].

This paper is organized as follows. In Section 2, we construct the production of three enterprises with differentiated products and independent competitive pricing in an economic monopoly industry. We theoretically analyze the system through the theory of complexity in Section 3. In Section 4, we use numerical simulation to demonstrate the various dynamic behaviors of the three-dimensional system and by time-delay feedback control to control the chaotic behavior of dynamical systems and numerical analysis show that effective and efficient control of power system can be unstable behavior. Finally, the main conclusions of this study are given.

\section{Model Specification}

This paper considers the production of three enterprises with differentiated products and independent competitive pricing in an economic monopoly industry. $q_{i}$ denotes the output of the enterprise $i, p_{i}$ denotes the product price of the enterprise $i$, and the consumer utility function is of the form

$$
V\left(q_{1}, q_{2}, q_{3}\right)=u\left(q_{1}, q_{2}, q_{3}\right)-\sum_{i=1}^{3} p_{i} q_{i}
$$

where $u\left(q_{1}, q_{2}, q_{3}\right)$ represents the second strict concave function. During the research, we use the following form:

$$
\begin{aligned}
& u\left(q_{1}, q_{2}, q_{3}\right)=\alpha_{1} q_{1}+\alpha_{2} q_{2}+\alpha_{3} q_{3} \\
& -\frac{1}{2}\left(\beta_{1} q_{1}^{2}+\beta_{2} q_{2}^{2}+\beta_{3} q_{3}^{2}+2 \gamma_{12} q_{1} q_{2}+2 \gamma_{13} q_{1} q_{3}+2 \gamma_{23} q_{2} q_{3}\right) .
\end{aligned}
$$

To simplify calculations, let $\alpha_{1}=\alpha_{2}=\alpha_{3}=a>0$, $\beta_{1}=\beta_{2}=\beta_{3}=1$, and $\gamma_{12}=\gamma_{13}=\gamma_{23}=d(-(1 / 2)<d<1)$.

By equations (1) and (2), the inverse requirement function can be obtained as follows:

$$
\left\{\begin{array}{l}
p_{1}=a-q_{1}-d q_{2}-d q_{3}, \\
p_{2}=a-q_{2}-d q_{1}-d q_{3}, \\
p_{3}=a-q_{3}-d q_{1}-d q_{2} .
\end{array}\right.
$$

From equation (3), the corresponding requirements can be obtained as follows:

$$
\left\{\begin{array}{l}
q_{1}=\frac{a}{1+2 d}-\frac{(1+d) p_{1}}{(1-d)(1+2 d)}+\frac{d p_{2}}{(1-d)(1+2 d)}+\frac{d p_{3}}{(1-d)(1+2 d)} \\
q_{2}=\frac{a}{1+2 d}-\frac{(1+d) p_{2}}{(1-d)(1+2 d)}+\frac{d p_{1}}{(1-d)(1+2 d)}+\frac{d p_{3}}{(1-d)(1+2 d)} \\
q_{3}=\frac{a}{1+2 d}-\frac{(1+d) p_{3}}{(1-d)(1+2 d)}+\frac{d p_{2}}{(1-d)(1+2 d)}+\frac{d p_{1}}{(1-d)(1+2 d)}
\end{array}\right.
$$

From equation (4), we can know that when $d=0$, the products are the most independent of each other and each enterprise is a monopolist in the market relative to other products; when $-(1 / 2)<d<0$, it indicates that the product is a complementary product; when $0<d<1$, it indicates that the products are substitutes for each other; when $d=1$, it means the exact same product.

Assume that the linear production cost function of enterprise $i$ is as follows:

$$
C\left(q_{i}\right)=\frac{c_{i}}{1+r_{i}} q_{i}
$$

where $c_{i}>0$ represents the parameters related to the production technology level of the enterprise. The higher the level of production technology is the smaller $c_{i}$ will be. $r_{i} \geq 0$ represents the parameter of the enterprise knowledge absorption capacity effect, which indicates the absorption of external knowledge and technology by the enterprise $i$ and thus the positive cost externality of the enterprise $i$.

Therefore, the profit that can be obtained from the enterprise $i$ can be expressed as follows:

$$
\prod_{i}=p_{i} q_{i}-\frac{c_{i}}{1+r_{i}} q_{i}=\left(p_{i}-\frac{c_{i}}{1+r_{i}}\right)\left(\frac{a}{1+2 d}-\frac{(1+d) p_{i}-d \sum_{j=1, j \neq i}^{3} p_{j}}{(1-d)(1+2 d)}\right), \quad i=1,2,3 .
$$


Then the marginal profit of enterprise $i$ in the $t$ period is as follows:

$$
\frac{\partial \prod_{i}}{\partial p_{i}}=\frac{(1-d) a-2(1+d) p_{i}+d \sum_{j=1, j \neq i}^{3} p_{j}+(1+d)\left(c_{i} / 1+r_{i}\right)}{(1-d)(1+2 d)}, \quad i=1,2,3
$$

Now, suppose that the decision rule of enterprise 1 is based on marginal profit, the decision rule of enterprise 2 is to follow the expected value of Naïve, and the decision rule of enterprise 3 is to adopt the maximized expected value of Naïve under the adaptive expectation plan. So, how to adjust the price of enterprise 1 mainly depends on whether the current marginal profit is positive or negative in $t+1$ the period. Therefore, enterprise 1 adjusts the decision mechanism over time as follows:

$$
\begin{array}{ll} 
& p_{1}(t+1)=p_{1}(t)+\alpha\left(p_{1}(t)\right) \frac{(1-d) a-2(1+d) p_{1}+d\left(p_{2}+p_{3}\right)+(1+d)\left(c_{1} / 1+r_{1}\right)}{(1-d)(1+2 d)} \\
& \quad p_{2}(t+1)=\frac{(1-d) a+d\left(p_{1}(t)+p_{3}(t)\right)+(1+d)\left(c_{2} / 1+r_{2}\right)}{2(1+d)} .
\end{array}
$$

where $\alpha\left(p_{1}(t)\right)=\alpha p_{1}(t)(\alpha>0)$ indicates the speed at which enterprise 1 adjusts the price based on marginal profit.

The decision rules for the enterprise 2 to adjust product prices over time are as follows:

$$
p_{2}(t+1)=\arg \max _{p_{2}} \prod_{2}\left(p_{1}^{e}(t+1), p_{2}(t), p_{3}^{e}(t+1)\right) .
$$

Substituting equation (6) into equation (9) yields the maximum expected value of Naïve in the following form:
Finally, suppose that enterprise 3 adopts the adaptive expectation decision rule to adjust the product price (i.e., when it determines the price of the product in the next period, it is based on its own price decision in the previous period and the Naïve expected value decision in the previous period); it can be expressed in the following form:

$$
p_{3}(t+1)=(1-\beta) p_{3}(t)+\beta \frac{(1-d) a+d\left(p_{1}(t)+p_{2}(t)\right)+(1+d)\left(c_{3} / 1+r_{3}\right)}{2(1+d)},
$$

where $0<\beta<1$ represents the coefficient of adaptive adjustment. If $\beta=0$, then the level of the price remains permanent; when $\beta=1$ it indicates the price level is the maximum expected value of Naïve.
From equations (8), (10), and (11), we can obtain the following dynamic system:

$$
\left\{\begin{array}{l}
p_{1}(t+1)=p_{1}(t)+\alpha p_{1}(t) \frac{(1-d) a-2(1+d) p_{1}+d\left(p_{2}+p_{3}\right)+(1+d)\left(c_{1} / 1+r_{1}\right)}{(1-d)(1+2 d)} \\
p_{2}(t+1)=\frac{(1-d) a+d\left(p_{1}(t)+p_{3}(t)\right)+(1+d)\left(c_{2} / 1+r_{2}\right)}{2(1+d)} \\
p_{3}(t+1)=(1-\beta) p_{3}(t)+\beta \frac{(1-d) a+d\left(p_{1}(t)+p_{2}(t)\right)+(1+d)\left(c_{3} / 1+r_{3}\right)}{2(1+d)}
\end{array}\right.
$$

A nonlinear discrete dynamical system (12) is obtained based on the assumption that the market inverse demand function and the production cost function are both linear forms. System (12) describes a price competition game relationship between three oligarchic enterprises with product differentiation and heterogeneous expectations. Under the condition of bounded rationality, the game subject will adjust the investment strategy of each period according to the marginal profit of the enterprise.

\section{Local Stability of Equilibrium Points}

In this section, firstly, the equilibrium points of the nonlinear discrete system (12) are calculated. Then, through qualitative 
Then, the stability characteristic equilibrium point of system (12) is analyzed qualitatively. Let $p_{i}(t+1)=p_{i}(t), i=1,2,3$.
Therefore, system (12) can be converted into the following form:

$$
\left\{\begin{array}{l}
\alpha p_{1} \frac{(1-d) a-2(1+d) p_{1}+d\left(p_{2}+p_{3}\right)+(1+d)\left(c_{1} / 1+r_{1}\right)}{(1-d)(1+2 d)}=0 \\
\frac{(1-d) a+d\left(p_{1}+p_{3}\right)+(1+d)\left(c_{2} / 1+r_{2}\right)}{2(1+d)}=p_{2} \\
-\beta p_{3}+\beta \frac{(1-d) a+d\left(p_{1}+p_{2}\right)+(1+d)\left(c_{3} / 1+r_{3}\right)}{2(1+d)}=0
\end{array}\right.
$$

By solving equation (13), the two equilibrium points of the complex dynamic system (12) are obtained as follows:

$$
\begin{aligned}
& E_{1}=\left(0, \frac{2(1+d)^{2} c_{2}\left(1+r_{3}\right)+\left(1+r_{2}\right)\left(a(2+3 d)(1-d)\left(1+r_{3}\right)+d(1+d) c_{3}\right)}{\left(4+8 d+3 d^{2}\right)\left(1+r_{2}\right)\left(1+r_{3}\right)}, \frac{2(1+d)^{2} c_{2}\left(1+r_{3}\right)+\left(1+r_{2}\right)\left(a(2+3 d)(1-d)\left(1+r_{3}\right)+d(1+d) c_{3}\right)}{\left(4+8 d+3 d^{2}\right)\left(1+r_{2}\right)\left(1+r_{3}\right)}\right), \\
& E_{2}=\left(q_{1}^{*}, q_{2}^{*}, q_{3}^{*}\right),
\end{aligned}
$$

where

$$
\begin{aligned}
& q_{1}^{*}=\frac{c_{1}\left(2+3 d+d^{2}\right)\left(1+r_{2}\right)\left(1+r_{3}\right)+a(1-d) m+d(1+d)\left(1+r_{1}\right)\left(c_{2}\left(1+r_{3}\right)+c_{3}\left(1+r_{2}\right)\right)}{2 m}, \\
& q_{2}^{*}=\frac{d(1+d)\left(1+r_{2}\right)\left(c_{1}\left(1+r_{3}\right)+c_{3}\left(1+r_{1}\right)\right)+\left(2+3 d+d^{2}\right) c_{2}\left(1+r_{3}\right)\left(1+r_{1}\right)+a(1-d) m}{2 m}, \\
& q_{3}^{*}=\frac{d(1+d)\left(1+r_{3}\right)\left(c_{1}\left(1+r_{2}\right)+c_{2}\left(1+r_{1}\right)\right)+\left(2+3 d+d^{2}\right) c_{3}\left(1+r_{2}\right)\left(1+r_{1}\right)+a(1-d) m}{2 m}, \\
& m=(2+3 d)\left(1+r_{1}\right)\left(1+r_{2}\right)\left(1+r_{3}\right) .
\end{aligned}
$$

It is easy to know that $E_{1}$ is the boundary equilibrium point and $E_{2}$ is the inner equilibrium point. Consider the realistic economic significance of system (12) equilibrium point representation. Therefore, only the case where the equilibrium point is nonnegative is discussed in the paper.
Since $a, c_{i}$, and $r_{i}$ are all positive parameters, both $E_{1}$ and $E_{2}$ are greater than zero.

Since the local stability of the equilibrium solution of the complex dynamic system (12) depends on the eigenvalues of the Jacobian matrix, first calculate the Jacobian matrix corresponding to system (12) as follows:

$$
J=\left[\begin{array}{ccc}
1+\frac{\alpha\left((1+d) c_{1}-\left(a(1-d)-4(1+d) p_{1}+d p_{2}+d p_{3}\right)\left(1+r_{1}\right)\right)}{(1-d)(1+2 d)\left(1+r_{1}\right)} \frac{d \alpha p_{1}}{(1-d)(1+2 d)} & \frac{d \alpha p_{1}}{(1-d)(1+2 d)} \\
\frac{d}{2(1+d)} & 0 & \frac{d}{2(1+d)} \\
\frac{d \beta}{2(1+d)} & \frac{d \beta}{2(1+d)} & 1-\beta
\end{array}\right] .
$$


Lemma 1 (cf. [39]): in n-dimensional discrete dynamical system (17), the system equilibrium point $x^{*}$ is stable under the condition that all eigenvalues of the Jacobian matrix $J\left(x^{*}\right)$ of the right-end function of the dynamic system (17) satisfy $\left|\lambda_{n}\right|<1$.

$$
\left\{\begin{array}{l}
x_{1}(t+1)=f_{1}\left(x_{1}(t), x_{2}(t), \ldots, x_{n}(t)\right), \\
x_{2}(t+1)=f_{2}\left(x_{1}(t), x_{2}(t), \ldots, x_{n}(t)\right), \\
\ldots \\
x_{n}(t+1)=f_{n}\left(x_{1}(t), x_{2}(t), \ldots, x_{n}(t)\right) .
\end{array}\right.
$$

Next, the stability of the two equilibrium points of the complex dynamical system (12) will be further analyzed based on Lemma 1.

Proposition 1. The boundary equilibrium point $E_{1}$ is unstable (saddle point).

Proof: To prove this result, we calculate the Jacobian matrix (14) at the boundary equilibrium point $E_{1}$ as follows:

$$
J\left(E_{1}\right)=\left[\begin{array}{ccc}
1+\frac{\alpha\left(\left(4+12 d+11 d^{2}+3 d^{3}\right) c_{1}\left(1+r_{2}\right)\left(1+r_{3}\right)+\left(1+r_{1}\right)\left(\left(1+r_{2}\right)\left(2 d^{2}(1+d) c_{3}+a(1-d)(2+3 d)^{2}\left(1+r_{3}\right)\right)+4 d(1+d)^{2} c_{2}\left(1+r_{3}\right)\right)\right)}{(1-d)(1+2 d)\left(4+8 d+3 d^{2}\right)\left(1+r_{1}\right)\left(1+r_{2}\right)\left(1+r_{3}\right)} & 0 \\
\frac{d}{2(1+d)} & 0 & \frac{d}{2(1+d)} \\
\frac{d \beta}{2(1+d)} & \frac{d \beta}{2(1+d)} & 1-\beta
\end{array}\right] .
$$

The eigenvalues of the Jacobian matrix $J\left(E_{1}\right)$ are obtained by calculation as follows: $\lambda_{1}=1+\left(\alpha\left(\left(4+12 d+11 d^{2}+3 d^{3}\right)\right.\right.$ $c_{1}\left(1+r_{2}\right)\left(1+r_{3}\right)+\left(1+r_{1}\right)\left(\left(1+r_{2}\right)\left(2 d^{2}(1+d) c_{3}+a(1-\right.\right.$ d) $\left.\left.\left.(2+3 d)^{2}\left(1+r_{3}\right)\right)+4 d(1+d)^{2} c_{2}\left(1+r_{3}\right)\right)\right) /(1-d)(1+$ $\left.2 d)\left(4+8 d+3 d^{2}\right)\left(1+r_{1}\right)\left(1+r_{2}\right)\left(1+r_{3}\right)\right), \quad \lambda_{2,3}=1-\beta \pm$ $\sqrt{\left((1-\beta)^{2}+\left(d^{2} \beta /(1+d)^{2}\right)\right)} / 2$. From the previous assumptions, we can know the parameters $\alpha>0$ and $-(1 / 2)<d<1$, so we can derive $\lambda_{1}>1$. Therefore, according to Lemma 1 , the discrete complex dynamic system (12) Nash equilibrium stability determination condition can be known that $E_{1}$ is an unstable boundary equilibrium. In addition, due to $0<\beta<1$, we can know $\left|\lambda_{2,3}\right|<1$.

The local stability of the Nash equilibrium solution is discussed below. The Jacobian matrix (16) at the inner point equilibrium solution $E_{2}$ is expressed as follows:

$$
J\left(E_{2}\right)=\left[\begin{array}{c}
(1+d) \alpha\left(\begin{array}{c}
\left(2+3 d+d^{2}\right) c_{1}\left(1+r_{2}\right)\left(1+r_{3}\right)+a(1-d) m \\
+d(1+d)\left(1+r_{1}\right)\left(c_{2}\left(1+r_{3}\right)+c_{3}\left(1+r_{2}\right)\right)
\end{array}\right) \\
(1-d)(1+2 d) m \\
\frac{d}{2(1+d)} \\
\frac{d \beta}{2(1+d)}
\end{array}\right.
$$

So, the characteristic polynomial of $J(O)$ is as follows. Let the characteristic polynomial of the matrix $J\left(E_{2}\right)$ be $G(\lambda)$, and the specific form of $G(\lambda)$ is as follows:
$G(\lambda)=\lambda^{3}+g_{1} \lambda^{2}+g_{2} \lambda^{1}+g_{3}$. Then, by calculation, the coefficients of the polynomial $G$ can be obtained as follows:

$$
\begin{aligned}
& g_{1}=\beta-2+\frac{(1+d) \alpha\left(\left(2+3 d+d^{2}\right) c_{1}\left(1+r_{2}\right)\left(1+r_{3}\right)+d(1+d)\left(1+r_{1}\right)\left(c_{2}\left(1+r_{3}\right)+\left(1+r_{2}\right) c_{3}\right)+a(1-d) m\right)}{(1-d)(1+2 d) m}, \\
& g_{2}=1-\beta-\frac{d^{2} \beta}{4(1+d)^{2}}-\frac{\alpha\left(d^{2}(1+\beta)+4(1+d)^{2}(1-\beta)\right)\left(\left(2+3 d+d^{2}\right) c_{1}\left(1+r_{2}\right)\left(1+r_{3}\right)+a(1-d) m+d(1+d)\left(1+r_{1}\right)\left(c_{2}\left(1+r_{3}\right)+c_{3}\left(1+r_{2}\right)\right)\right)}{4\left(1-d^{2}\right)(1+2 d) m} \\
& g_{3}=\frac{1}{4(1+d)^{2}} d^{2}\left(\beta+\frac{\alpha((1+d)(1+2 \beta)+d \beta)\left(\left(2+3 d+d^{2}\right) c_{1}\left(1+r_{2}\right)\left(1+r_{3}\right)+a(1-d) m+d(1+d)\left(1+r_{1}\right)\left(c_{2}\left(1+r_{3}\right)+\left(1+r_{2}\right) c_{3}\right)\right)}{(1-d)(1+2 d) m}\right) .
\end{aligned}
$$

It can be known from the Schur-Cohn stability criterion that if the characteristic polynomial $G(\lambda)$, that is, all the eigenvalues of the Jacobian matrix $J\left(E_{2}\right)$, is located in the unit circle on the complex plane, the coefficients of the 
polynomial need to satisfy the conditions in the Schur-Cohn stability decision. Therefore, the system parameters are substituted into it and simplified:

$$
\begin{aligned}
G(1)= & 1+g_{1}+g_{2}+g_{3}=\left(( 2 + 3 d ) \alpha \beta \left(\left(2+3 d+d^{2}\right) c_{1}\left(1+r_{2}\right)\left(1+r_{3}\right)+a(1-d) m+d(1+d)\left(1+r_{1}\right)\right.\right. \\
& \left.\left.\cdot\left(c_{2}\left(1+r_{3}\right)+\left(1+r_{2}\right) c_{3}\right)\right)\right)\left(4(1-d)(1+d)^{2}(1+2 d)\left(1+r_{1}\right)\left(1+r_{2}\right)\left(1+r_{3}\right)\right)^{-1}, \\
G(-1)=1-g_{1}+g_{2}-g_{3}=4-2 \beta-\frac{d^{2} \beta}{2(1+d)^{2}}-\left(\alpha\left(d^{2}(1+\beta)+4(1+d)^{2}(2+\beta)+d \beta+(1+d)(2 \beta-1)\right)\right. & \left.\cdot\left(\left(2+3 d+d^{2}\right) c_{1}\left(1+r_{2}\right)\left(1+r_{3}\right)+a(1-d) m+d(1+d)\left(1+r_{1}\right)\left(c_{2}\left(1+r_{3}\right)+\left(1+r_{2}\right) c_{3}\right)\right)\right) \\
& \cdot(4(1-d)(1+d)(1+2 d) m)^{-1}, \\
\left\{\begin{array}{l}
1-g_{2}+g_{3} g_{1}-g_{3}^{2}>0, \\
1+g_{2}-g_{3} g_{1}-g_{3}^{2}>0,
\end{array}\right. & \left\{\begin{array}{l}
1-g_{2}+g_{3} g_{1}-g_{3}^{2}>0, \\
3-g_{2}>0 .
\end{array}\right.
\end{aligned}
$$

Proposition 2. The Bertrand-Nash equilibrium solution $E_{2}$ of the complex dynamical system (12) is locally asymptotically stable if there is

$$
\alpha<\alpha^{C}=\frac{2 m(1-d)(1+2 d)\left[\beta\left(4+8 d+5 d^{2}\right)-8(1+d)^{2}\right]}{\left(\beta(2+3 d)\left(2+3 d+2 d^{2}\right)-2(1+d)\left(4+8 d+5 d^{2}\right)\right)\left(c_{1}\left(2+3 d+d^{2}\right)\left(1+r_{2}\right)\left(1+r_{3}\right)+a(1-d) m+d(1+d)\left(1+r_{1}\right)\left(c_{2}\left(1+r_{3}\right)+c_{3}\left(1+r_{2}\right)\right)\right)} .
$$

Proof. It is known from the positive and negative assumptions of the system parameters that $G(1)>0$ and $3-$ From $G(-1)=1-g_{1}+g_{2}-g_{3}>0$, we can infer $g_{2}>0$ are clearly established in stable conditions.

$\alpha<\alpha_{1}=\frac{2 m(1-d)(1+2 d)\left[\beta\left(4+8 d+5 d^{2}\right)-8(1+d)^{2}\right]}{\left(\beta(2+3 d)\left(2+3 d+2 d^{2}\right)-2(1+d)\left(4+8 d+5 d^{2}\right)\right)\left(c_{1}\left(2+3 d+d^{2}\right)\left(1+r_{2}\right)\left(1+r_{3}\right)+a(1-d) m+d(1+d)\left(1+r_{1}\right)\left(c_{2}\left(1+r_{3}\right)+c_{3}\left(1+r_{2}\right)\right)\right)}$.

Now, we will discuss the inequality $1-g_{2}+g_{3} g_{1}-$ $g_{3}^{2}>0$. Firstly, we consider that $1-g_{2}+g_{3} g_{1}-g_{3}^{2}=0$ is a quadratic function about $\alpha$, and under the initial assumptions, the discriminant is nonnegative, so the equation $1-$ $g_{2}+g_{3} g_{1}-g_{3}^{2}=0$ has two real roots $\alpha_{2}$ and $\alpha_{3}\left(\alpha_{3}<0\right)$. Figure 1 shows the region diagram where the sign of $\alpha_{2}$ changes with the change of $(d, \beta)$.

In addition, we can also know

$$
1-g_{2}+g_{3} g_{1}-g_{3}^{2}>0 \Longleftrightarrow \begin{cases}\alpha<\alpha_{2}, & \text { The white area in Figure } 1 \text { is shown, } \\ \forall \alpha>0, & \text { The red area in Figure } 1 \text { is shown. }\end{cases}
$$

When the parameter $(d, \beta)$ is in the white area, the thresholds $\alpha_{1}$ and $\alpha_{2}$ are compared, and $\alpha_{1}<\alpha_{2}$ is known.

From the above conclusions, we can conclude that the Nash equilibrium is locally asymptotically stable by adjusting the threshold of the following speeds:

$$
\alpha_{1}=\alpha^{B}=\frac{2 m(1-d)(1+2 d)\left[\beta\left(4+8 d+5 d^{2}\right)-8(1+d)^{2}\right]}{\left(\beta(2+3 d)\left(2+3 d+2 d^{2}\right)-2(1+d)\left(4+8 d+5 d^{2}\right)\right)\left(c_{1}\left(2+3 d+d^{2}\right)\left(1+r_{2}\right)\left(1+r_{3}\right)+a(1-d) m+d(1+d)\left(1+r_{1}\right)\left(c_{2}\left(1+r_{3}\right)+c_{3}\left(1+r_{2}\right)\right)\right)} .
$$

The local stability of Nash equilibrium is inferred from this proposition which largely depends on the adjustment speed of enterprise product price decision. If the company is overresponsive (i.e., the value of $\alpha$ is high), the Nash 


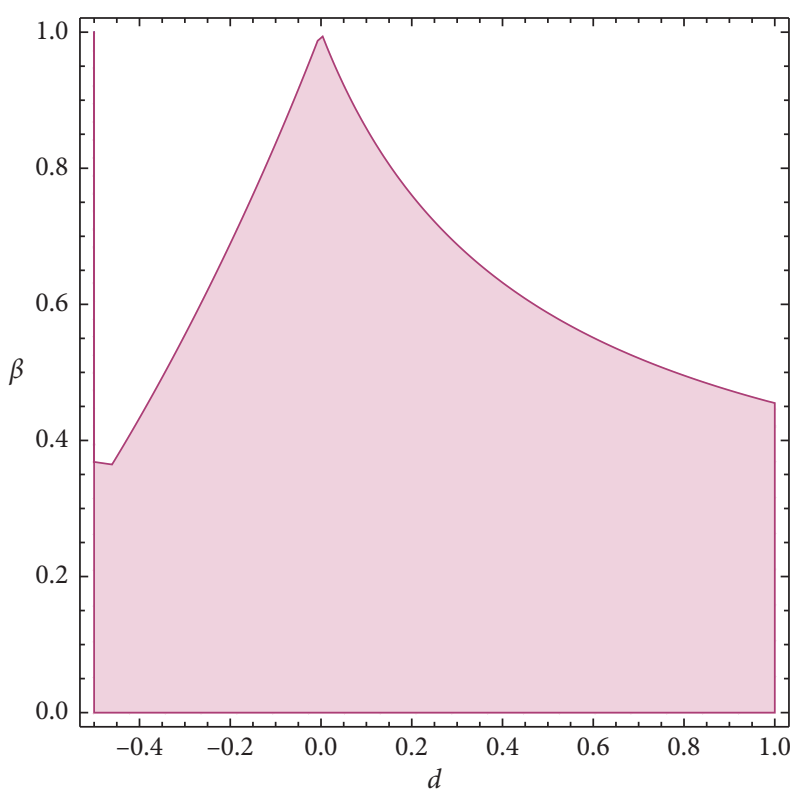

$\square \alpha_{2}>0$

$\square \alpha_{2}<0$

Figure 1: The region diagram where the sign of $\alpha_{2}$ changes with the change of $(d, \beta)$.

equilibrium loses stability and complex dynamic behavior may occur throughout the system. Therefore, it is also necessary to analyze the influence of other parameters on the threshold $\alpha^{C}$ to see if there are other more interesting dynamic behaviors. Then, we will discuss the effect of $\beta$ and $d$ on the threshold $\alpha^{C}$.

For (22), the partial derivative is obtained for $\beta$. The result is as follows:

$$
\begin{aligned}
\frac{\partial \alpha^{B}}{\partial \beta}= & -\left(4 d^{2}(1-d)(1+d)(2+d)^{2}(1+2 d) m\right)\left(\left(4(2-\beta)+12 d(2-\beta)+13 d^{2}(2-\beta)+2 d^{3}(5-3 \beta)\right)^{2}\right. \\
& \left.\cdot\left(d c_{3}(1+d)\left(1+r_{1}+r_{2}+r_{1} r_{2}\right)+d(1+d) c_{2}\left(1+r_{1}\right)\left(1+r_{3}\right)+\left(2+3 d+d^{2}\right) c_{1}\left(1+r_{2}\right)\left(1+r_{3}\right)+a m(1-d)\right)\right)^{-1}<0 .
\end{aligned}
$$

There is a hypothesis that $\beta=1$ represents the Nash expected value of the product price level. Then, the higher the value of the product price adjustment speed parameter $\beta$ is, the more the decision-makers of enterprise 3 tend to change the product price of the previous period, which leads to the phenomenon of system instability.

Now discuss the impact of product differentiation, and obtain the following equation by calculation:

$$
\begin{aligned}
\frac{\partial \alpha^{C}}{\partial d}= & \left(2 m \left(\left((2+3 d)\left(2+3 d+2 d^{2}\right) \beta-2(1+d)\left(4+8 d+5 d^{2}\right)\right)(2(1-d)((1+2 d)(\beta(4+5 d)-8(1+d))\right.\right. \\
& +\left(4+8 d+5 d^{2}\right) \beta-8(1+d)^{2}-(1+2 d)\left(\left(4+8 d+5 d^{2}\right) \beta-8(1+d)^{2}\right)-2(1-d)(1+2 d)((2-\beta)(6+13 d) \\
& \left.\left.+3 d^{2}(5-3 \beta)\right)\left(4(2-\beta)(1+2 d)+d^{2}(8-5 \beta)\right) p_{1}^{*}\right)-(1-d)(1+2 d)\left(\left(4+8 d+5 d^{2}\right) \beta-8(1+d)^{2}\right) \\
& \left.\left.\cdot\left((1+2 d)\left(1+r_{1}\right)\left(c_{3}\left(1+r_{2}\right)+c_{2}\left(1+r_{3}\right)\right)-a m+(3+2 d) c_{1}\left(1+r_{2}\right)\left(1+r_{3}\right)\right)\right)\right) \\
& \cdot\left(( - 2 ( 1 + d ) ( 4 + 8 d + 5 d ^ { 2 } ) + ( 2 + 3 d ) ( 2 + 3 d + 2 d ^ { 2 } ) \beta ) \left(a(1-d) m+\left(2+3 d+d^{2}\right) c_{1}\left(1+r_{2}\right)\left(1+r_{3}\right)\right.\right. \\
& \left.\left.+d(1+d)\left(1+r_{1}\right)\left(c_{3}\left(1+r_{2}\right)+c_{2}\left(1+r_{3}\right)\right)\right)^{2}\right)^{-1} .
\end{aligned}
$$




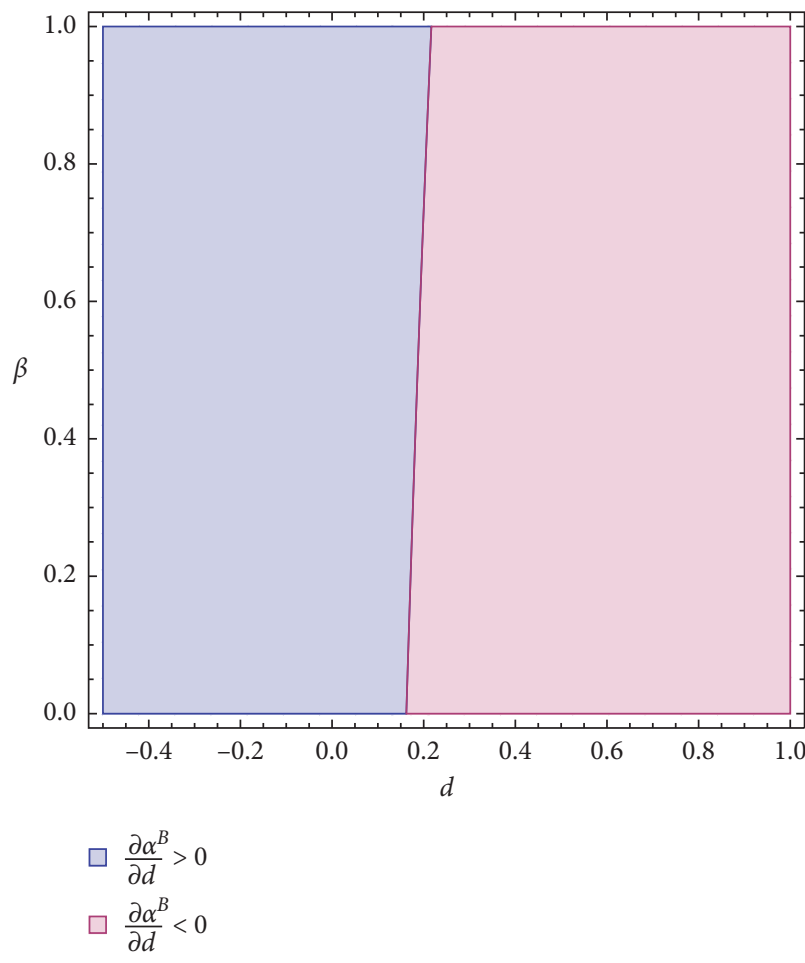

(a)

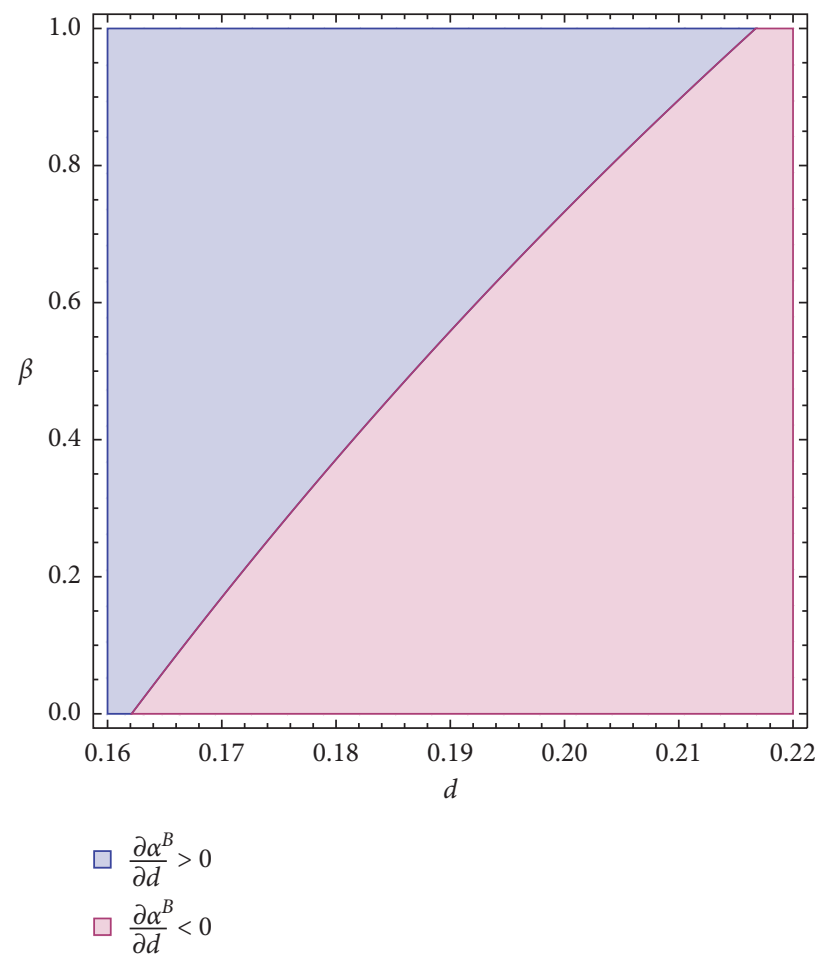

(b)

Figure 2: Symbol area of $\partial \alpha^{B} / \partial d$.

The complex dynamic phenomena that emerge from system (12) under different parameters are also very different. For the convenience of research, let the parameters $a=3, c_{1}=1, c_{2}=0.8, c_{3}=0.6, r_{1}=2, r_{2}=1.5$, and $r_{3}=1$. Therefore, we can get the sign change curve of Eq. (20) on the parameter plane $(d \beta)$ as follows:

$\beta^{B}(d)=\frac{\left(\begin{array}{c}2.4325-8.063 d-132.6634 d^{2}-490.2729 d^{3}-895.526 d^{4}-908.1373 d^{5}-502.1122 d^{6}-121.4874 d^{7}+9.9104 d^{8}+11.8392 d^{9}+1.5 d^{10} \\ -\sqrt{2.3175 \times 10^{9}+1.26 \times 10^{10} d-4.0064 \times 10^{9} d^{2}-1.888 \times 10^{11} d^{3}-5.6044 \times 10^{11} d^{4}-4.476 \times 10^{11} d^{5}+1.3107 \times 10^{12} d^{6}+4.7838 \times 10^{12} d^{7}} \\ +7.9657 \times 10^{12} d^{8}+8.3286 \times 10^{12} d^{9}+5.4163 \times 10^{12} d^{10}+1.3828 \times 10^{12} d^{11}-1.1999 \times 10^{12} d^{12}-1.6013 \times 10^{12} d^{13}-8.5036 \times 10^{11} d^{14} \\ -1.5501 \times 10^{11} d^{15}+8.6023 \times 10^{10} d^{16}+7.1706 \times 10^{10} d^{17}+2.4224 \times 10^{10} d^{18}+4.0467 \times 10^{9} d^{19}+2.5635 \times 10^{8} d^{20}\end{array}\right.}{\left(-1.0388-10.3774 d-58.3204 d^{2}-194.4287 d^{3}-374.49 d^{4}-404.4785 d^{5}-223.4387 d^{6}-42.2996 d^{7}+13.21 d^{8}+9.6706 d^{9}+d^{10}\right)}$.

In Figure 2, (b) is magnification of (a) in the $0.16 \leq d \leq 0.22$ interval. As can be seen from Figure 2, the curve (22) divides the parameter plane into two regions: the blue region represents $\partial \alpha^{C} / \partial d>0$ and the pink region represents $\partial \alpha^{\mathrm{C}} / \partial d<0$.

In the complementary commodity $(d<0)$, the complementarity of the product is reduced (i.e., $d$ tends to 0 ), and the Nash equilibrium is increased. On the contrary, this monotonic relationship does not appear in the substitute product. In this case, the threshold for adjusting the speed is the largest and has a certain degree of substitutability (for the fixed $\beta$ ); if the degree of difference between the products is increased, the stability of the Nash equilibrium is difficult to be guaranteed (note: $d$ is true when the value approaches 0 on the right side). In the mutual substitution, this result is related to the complementary intertemporal strategy of the product.

\section{Numerical Simulation and Chaos Control}

In order to better demonstrate the complex dynamic evolution behavior of the nonlinear dynamic system (12), the numerical simulation of the system will be carried out. We will give the evolution trajectory diagram, bifurcation diagram, attractor chaotic diagram, system sensitivity dependence of the nonlinear dynamic system, and so forth. Because the chaotic behavior is irregular and disordered, its trajectory cannot be judged. In addition, the generation of chaos will also have an unpredictable impact on the management system, so this 


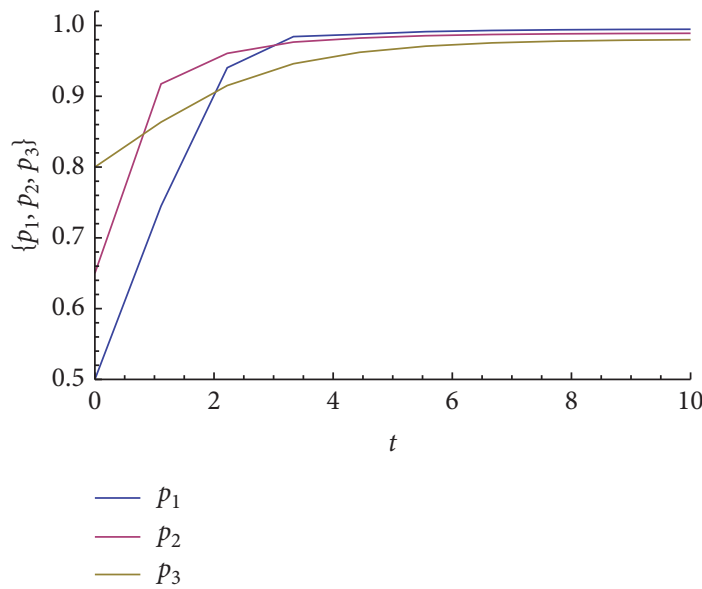

(a)

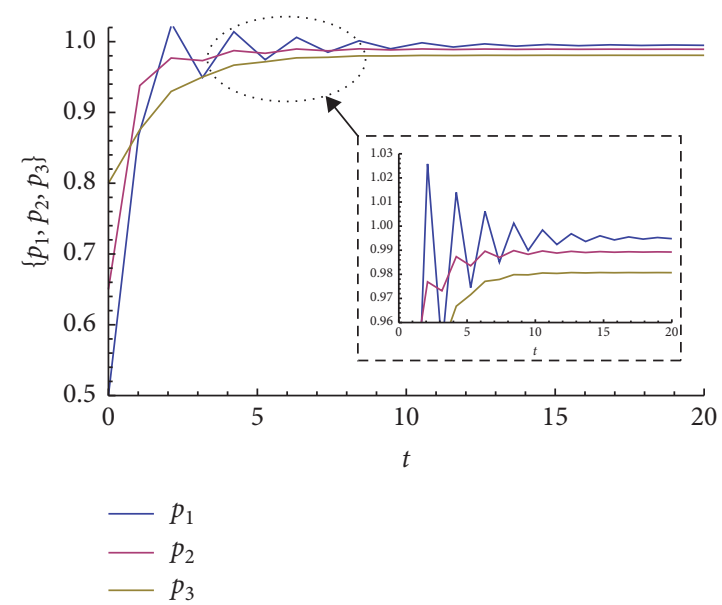

(b)

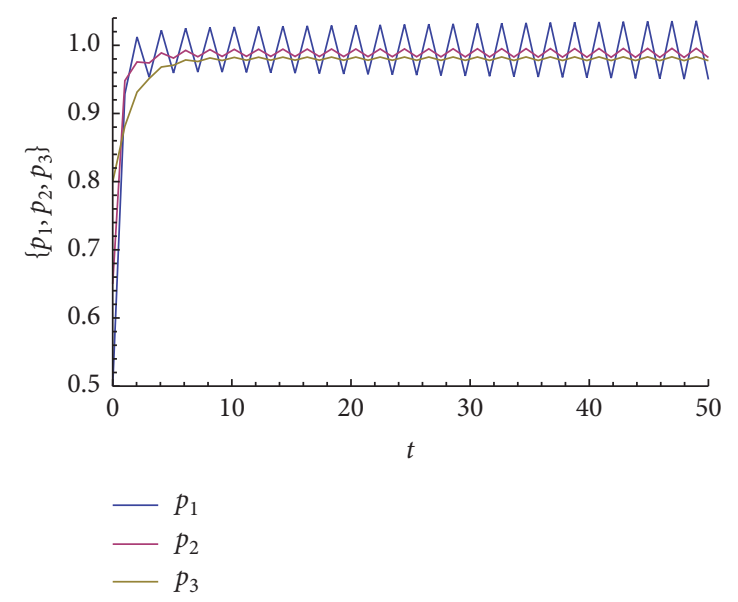

(c)

Figure 3: $p_{1}, p_{2}, p_{3}$ trajectory change with time at different adjustment speeds of enterprise 1 . (a) $\alpha=0.4$. (b) $\alpha=0.6$. (c) $\alpha=0.7$.

section uses the feedback control method to control the nonlinear dynamic system and gives theoretical proof.

4.1. Numerical Simulation. In this section, the dynamic evolution of the nonlinear dynamical system (12) is numerically simulated, and the dynamic evolution process is visualized by simulation results such as bifurcation diagram, stable region, singular attractor, and the speed at which the system converges to the equilibrium point. Convenient for comparative analysis, based on the previous parameter assumptions, some of the system parameter values in this section are determined as follows: $d=0.5$ and $\beta=0.5$.

Figure 3 shows that as the adjustment speed parameter $\alpha$ of enterprise 1 increases, the oscillation of the Nash equilibrium of system (12) causes more and more complex dynamic behaviors. The attractor in Figure 3(a) is Nash equilibrium, and Figures 3(b) and 3(c) show the complex behavior exhibited by the system when the period-doubling bifurcation leads to chaos. Figure 4 shows the phase diagram of singular attractor corresponding to Figure 3(c).

Figure 5 shows bifurcation diagram in which the Nash equilibrium of the nonlinear dynamic system (12) loses stability and the complexity of the singular attractors increases as the adjustment speed $\alpha$ of enterprise 1 increases. When the value of $\alpha$ gradually increases from 0 , the Nash equilibrium point of the nonlinear dynamic system (12) begins to become unstable at $\alpha=0.4831$ and enters the chaotic state after bifurcation. When $\alpha>0.65$, the evolution of the nonlinear dynamic system (12) collapses due to negative price. From the economic point of view, participants can withdraw from the commodity market for explanation.

In Figure 6, the effect of the parameter $d$ on the Nash equilibrium of the nonlinear dynamic system (12) is illustrated by simulation in an alternative commodity. The greater the difference between commodities is (i.e., $d$ approaches 0 ), the small the competition between market products is, and the Nash equilibrium point of the nonlinear dynamic system (12) is more stable. On the contrary, when the product differentiation is reduced (i.e., $d$ approaches 1 ), the Nash equilibrium point of the nonlinear dynamic system (12) becomes unstable, which also indicates that the product differentiation is small, resulting in more intense market competition and unstability. It can be explained that increasing the degree of product differentiation makes the 

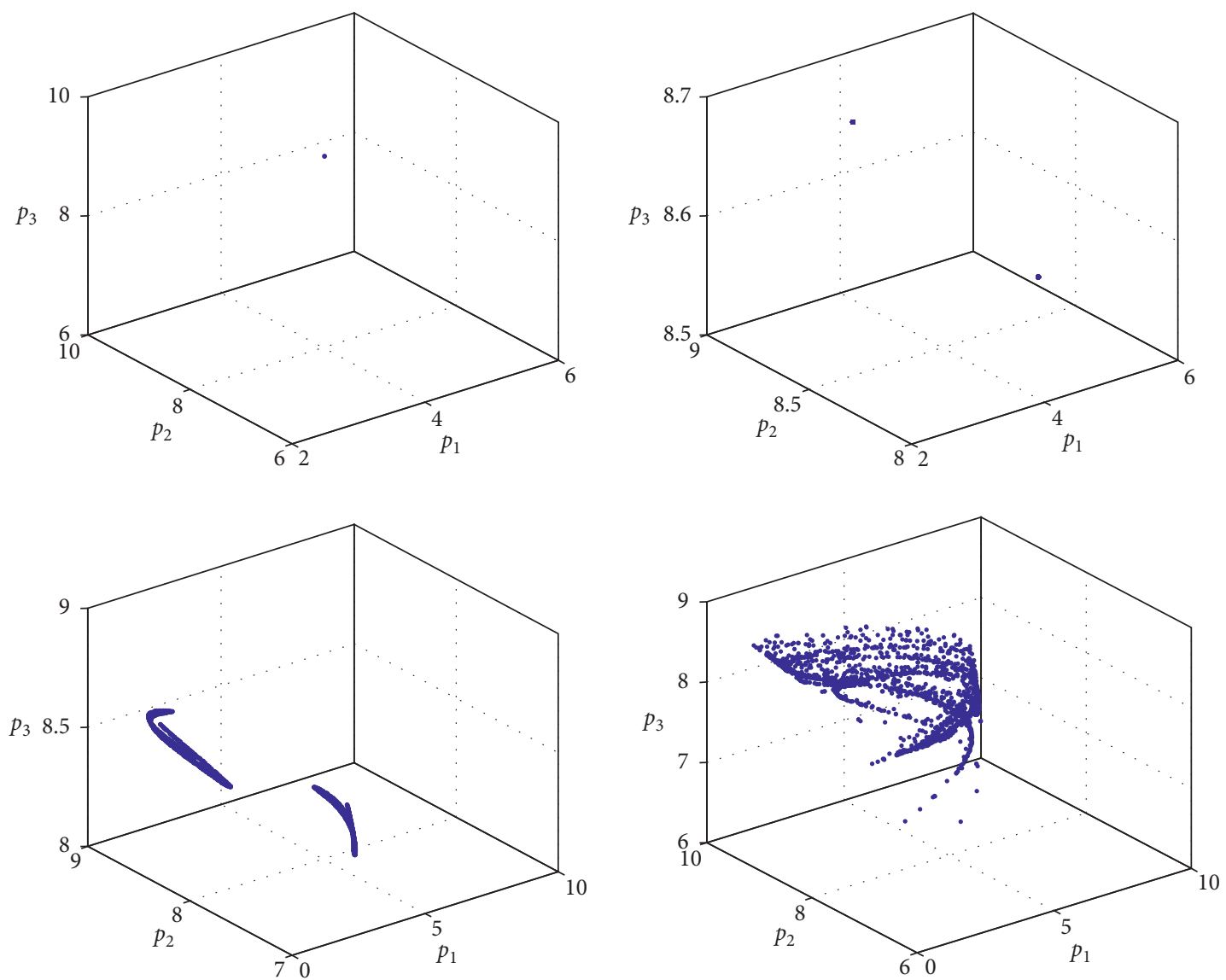

Figure 4: Chaotic attractor of the nonlinear dynamic system (12). (a) $\alpha=0.2$. (b) $\alpha=0.5$. (c) $\alpha=0.65$. (d) $\alpha=0.7$.

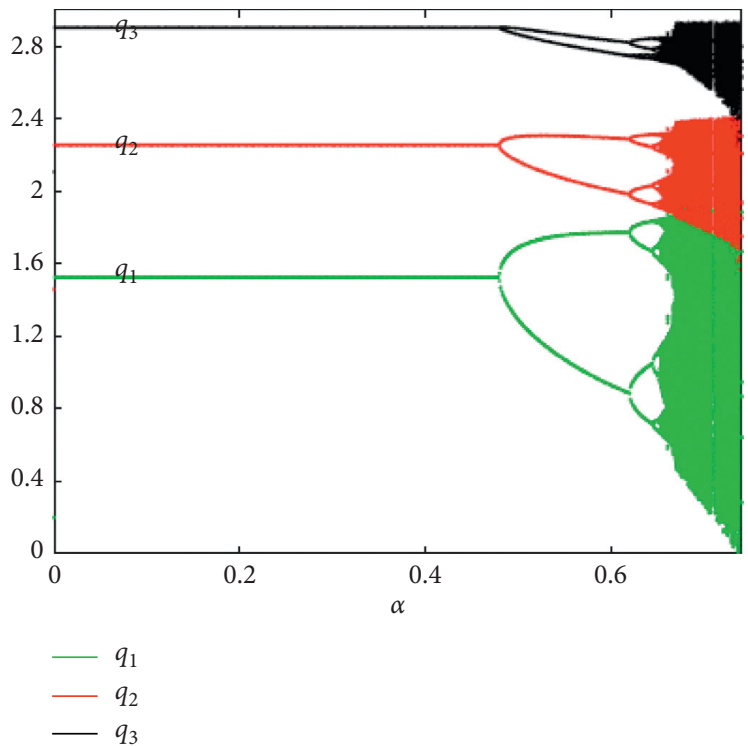

FIgURE 5: Bifurcation diagram of the nonlinear dynamic system (12) with $\alpha$ changes.

enterprise to improve its own competitive advantage, and increasing product differentiation requires enterprises to have more investment in technology and innovation. Product differentiation is also an important factor in regulating market stability. In addition, when the enterprise responds faster to the market under the same conditions, it will increase the market instability. If individuals adjust their own decisions and get more profits in the enterprise group, 

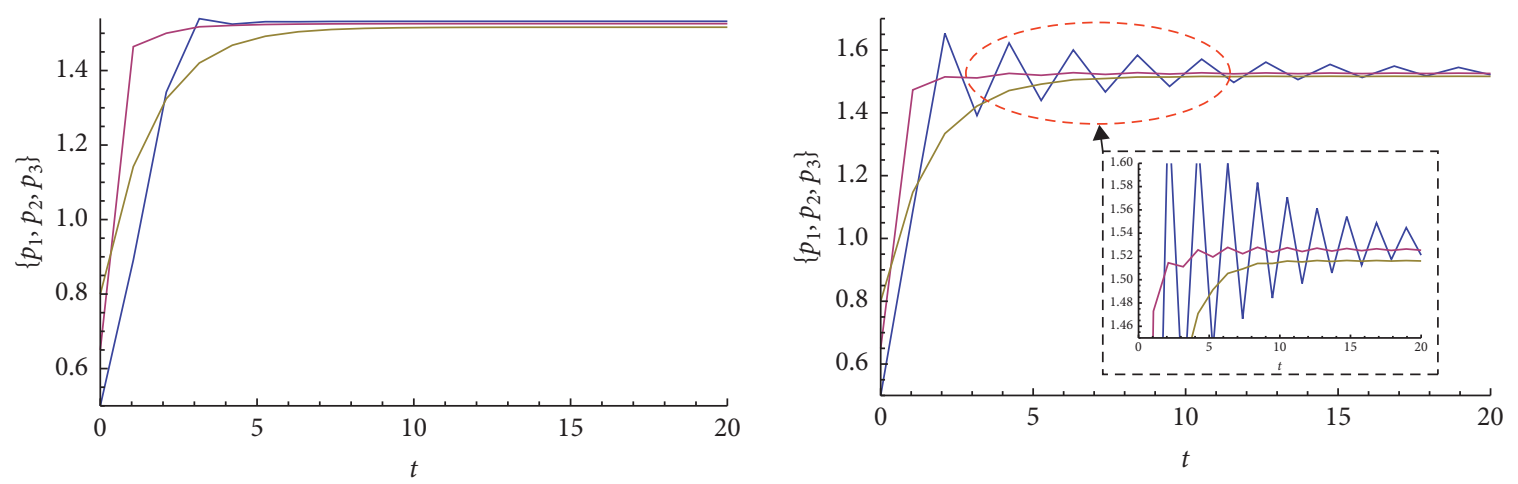

$-p_{1}$
$-p_{2}$
$-p_{3}$

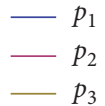

(a)
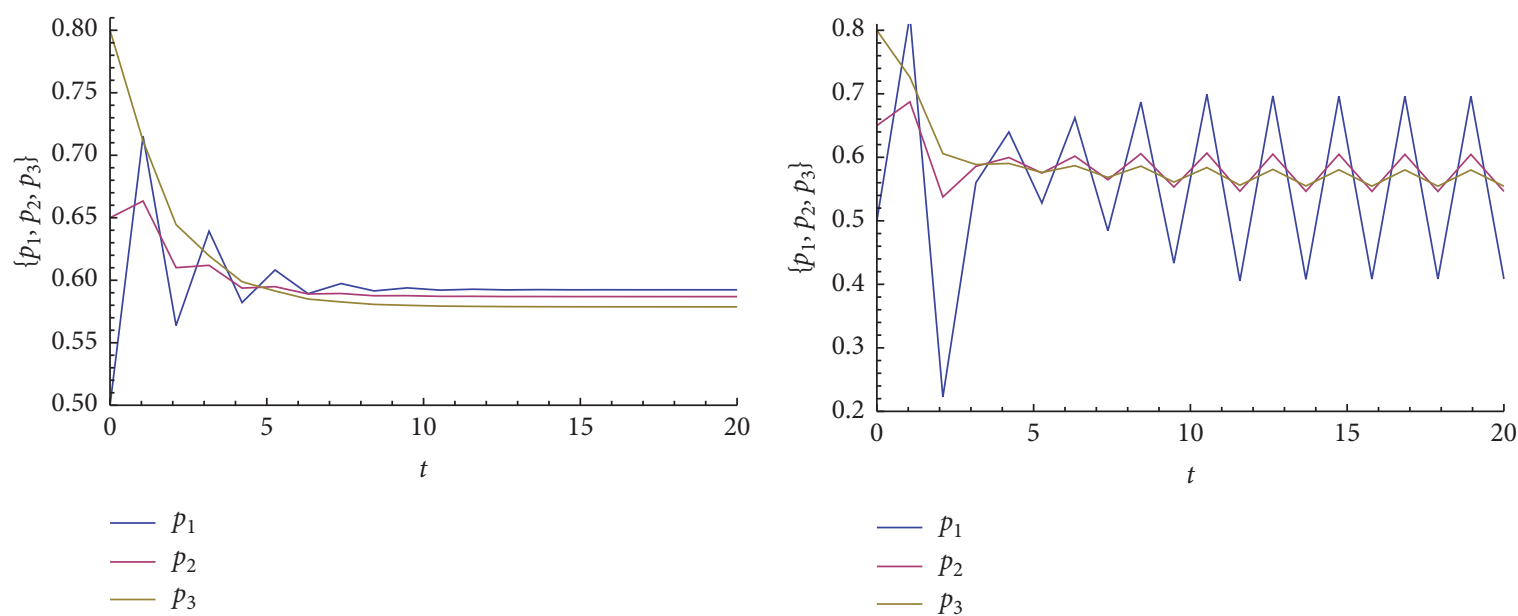

(c)

(d)

Figure 6: The trajectory changes of $p_{1}, p_{2}, p_{3}$ over time under the difference $d$ of product. (a) $\alpha=0.4, d=0.1$. (b) $\alpha=0.4, d=0.7$. (c) $\alpha=0.6, d=0.1$. (d) $\alpha=0.6, d=0.7$.

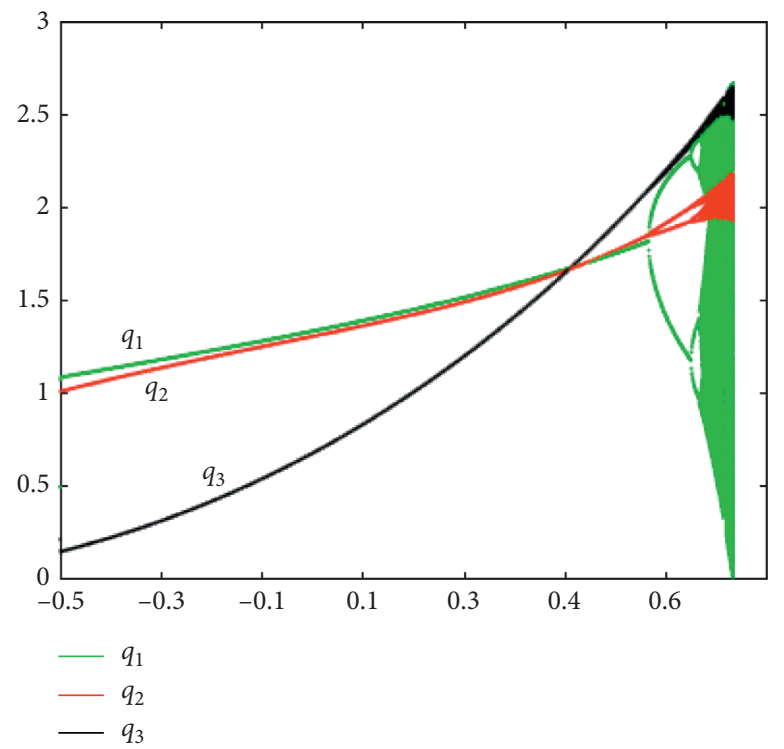

Figure 7: The bifurcation diagram of the nonlinear dynamic system (12) with $d$ changes. 

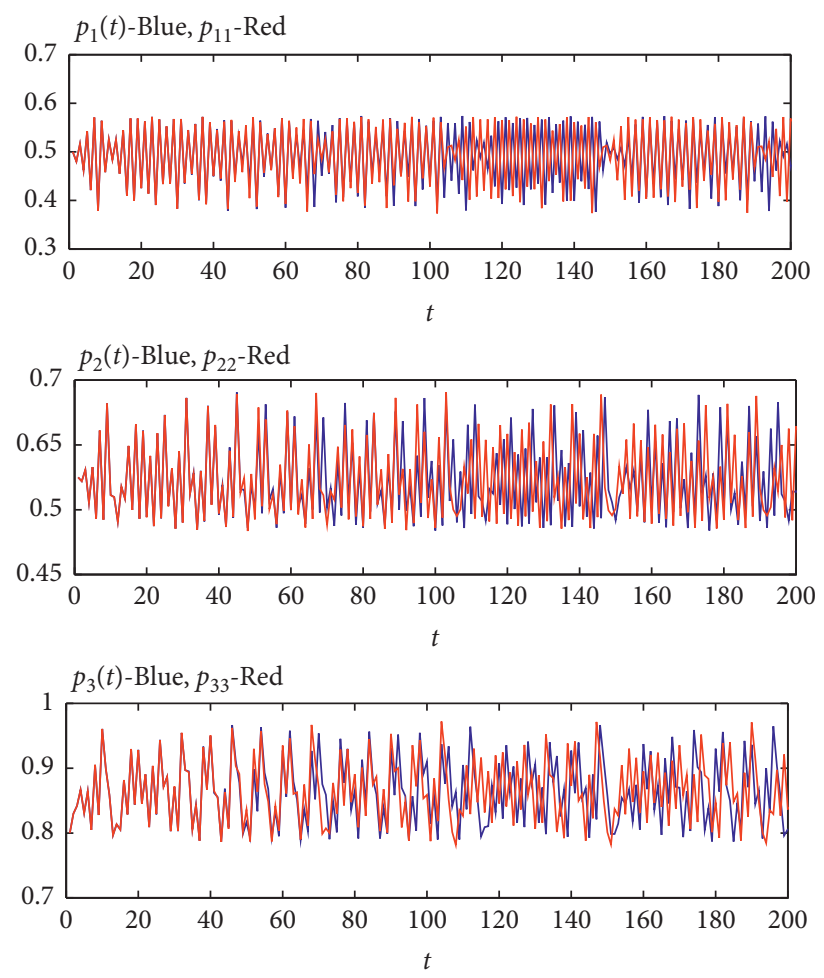

FIGURE 8: Sensitivity analysis of the nonlinear dynamic system (12) corresponding to the initial value.

other individuals will compare and follow the learning to adjust their strategies, which will lead to the unstable phenomenon of the market.

Figure 7 shows bifurcation diagram in which the Nash equilibrium of the nonlinear dynamic system (12) loses stability and the complexity of the singular attractors increases as the difference $d$ of product changes. When the value of $\alpha$ gradually increases from 0.5 , the Nash equilibrium point of the nonlinear dynamic system (12) begins to become unstable at $d=0.5755$. With the appearance of the bifurcation phenomenon, after the period-doubling bifurcation, it finally evolves into a chaotic state.

Figure 8 shows the iterative evolution of the state variable orbit over time for the dynamical system (12) under two slightly different initial conditions. It can be seen from Figure 8 that as the number of iterations increases, the orbits under the two initial values of the same state variable are gradually separated, and the nonlinear dynamic system (12) shows significant sensitivity dependence on the initial value.

4.2. Chaos Control. From the numerical simulation, we can know that the adjustment speed has a great influence on the stability of the nonlinear dynamic system (12) [40-42]. The dynamic behavior of system (12) will be more complicated if the model parameters cannot be located to the desired stable region. In the real economic system, chaos is unpredictable and unpredictable, so it needs to be avoided or controlled to make the dynamic system run better and better. Next, the control method is introduced by the time-delay feedback control to control the chaotic behavior of system (12). First, system (12) is embedded in the controller $k\left(q_{1}(t)-q_{1}(t+1)\right)$, where $K>0$ is the control parameter. Then the controlled system (12) changes to the following form:

$$
\left\{\begin{array}{l}
p_{1}(t+1)=p_{1}(t)+\alpha p_{1}(t) \frac{(1-d) a-2(1+d) p_{1}+d\left(p_{2}+p_{3}\right)+(1+d)\left(c_{1} / 1+r_{1}\right)}{(1-d)(1+2 d)}+k\left(p_{1}(t)-p_{1}(t+1)\right) \\
p_{2}(t+1)=\frac{(1-d) a+d\left(p_{1}(t)+p_{3}(t)\right)+(1+d)\left(c_{2} / 1+r_{2}\right)}{2(1+d)} \\
p_{3}(t+1)=(1-\beta) p_{3}(t)+\beta \frac{(1-d) a+d\left(p_{1}(t)+p_{2}(t)\right)+(1+d)\left(c_{3} / 1+r_{3}\right)}{2(1+d)}
\end{array}\right.
$$
follows:

The Jacobian matrix of the controlled system (29) is as 


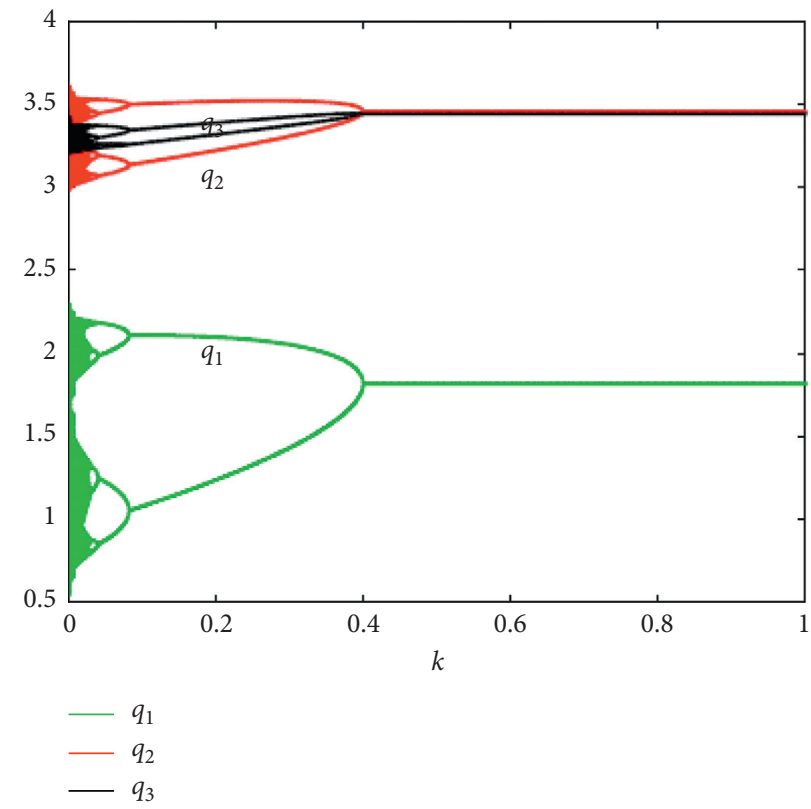

FIgURE 9: Corresponding bifurcation diagram of system (29) with control parameter $k$.
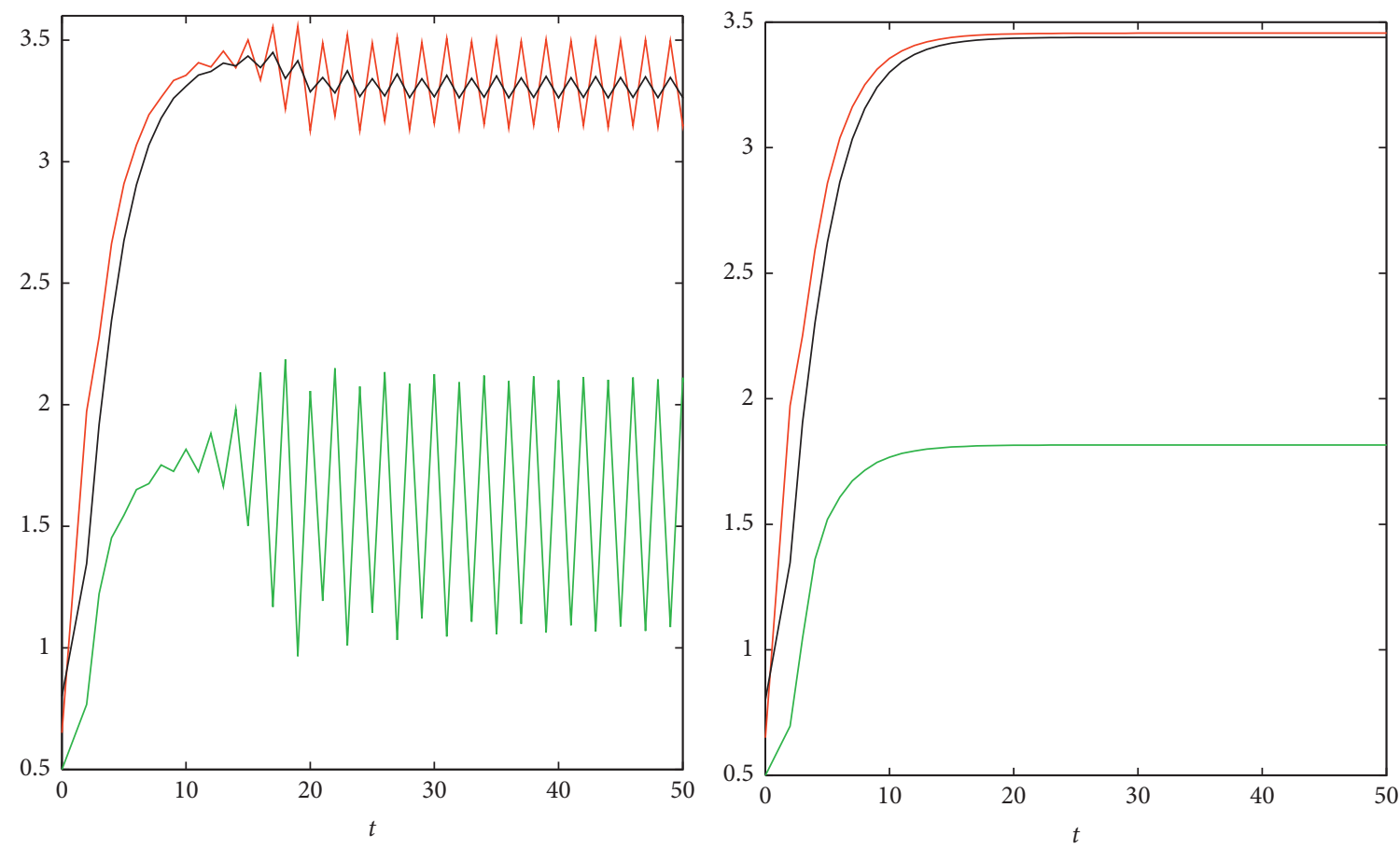

$$
\begin{array}{r}
-q_{1} \\
-q_{2} \\
-q_{3}
\end{array}
$$

FIGURE 10: The evolution trajectory of control parameters $k=0.1$ and $k=0.5$ the dynamical system (29) with time. 


$$
J=\left[\begin{array}{ccc}
1+\frac{(\alpha / 1+k)\left((1+d) c_{1}-\left(a(1-d)-4(1+d) p_{1}+d p_{2}+d p_{3}\right)\left(1+r_{1}\right)\right)}{(1-d)(1+2 d)\left(1+r_{1}\right)} & \alpha d p_{1} \\
\frac{d}{2(1+d)} & \left.\frac{d d p_{1}}{(1+k)(1-d)(1+2 d)} \frac{d}{2(1+k)(1-d)(1+2 d)}\right] \\
\frac{d \beta}{2(1+d)} & \frac{d \beta}{2(1+d)} & 1-\beta
\end{array}\right],
$$

It can be seen from Figure 5 that when enterprise 1 adjusts the parameter $\alpha>0.65$, the nonlinear dynamic system (12) starts to become unstable and accompanied the occurrence of chaotic behavior, so in the control system, let $\alpha=0.7$. Substitute the parameters into the Jacobian matrix and calculate the following form:

$$
J=\left[\begin{array}{ccc}
1-2.0895 / 1+k & 0.3483 / 1+k & 0.3483 / 1+k \\
0.1667 & 0 & 0.1667 \\
0.0833 & 0.0833 & 0.5
\end{array}\right] .
$$

The eigenvalue of the entire matrix is less than 1 , which indicates that the set of parameter values of the dynamic system (29) is stable, so the chaotic control of the control system (12) tends to stable orbit. As can be seen from the stability conditions, the eigenvalues of the Jacobian matrix need to satisfy $\left|\lambda_{i}\right|<1,(i=1,2,3)$, thus solving $k>0.4025$. Therefore, when $k$ increases, the controlled system (29) will gradually reach stable state.

In Figure 9, with the increase of the control parameter $k$, system (29) gradually tends to be stable from chaos and quasi-period. When $k>0.4025$, system (29) finally evolves to be stable. When $k=0.1$ and $k=0.5$, their respective characteristic values are $\left|\lambda_{1}\right|=0.9665,\left|\lambda_{2}\right|=0.5576$, and $\left|\lambda_{3}\right|=$ 0.0095 and $\left|\lambda_{1}\right|=0.5615,\left|\lambda_{2}\right|=0.482$, and $\left|\lambda_{3}\right|=0.0275$. Figure 10 shows the behavior of the track stability of the control system (29) with other parameters unchanged. These two graphs can find stable regions. As the feedback strength value increases, the chaotic behavior can be quickly controlled to stable orbit. This means that enterprise participants use time-delay feedback control to adjust strategies to quickly restore stable, orderly market competition.

\section{Conclusion}

In this paper, the dynamic properties of the three oligarchic games with product differentiation and heterogeneity are studied. Under the price competition, by studying the local stability of the equilibrium points, the following results were found.

First, under price competition, the behavior of gradient firms may constitute a source of instability. This phenomenon occurs when participants are more sensitive to market information and make their adjustments too fast. This result confirms the conclusions presented in the literature (see $[14,15,21,43]$, etc.).

Second, the adaptive expectations of enterprises have an impact on the stability or instability of the game model, because if enterprises are more inclined to change the number of previous periods, Nash equilibrium will lose local stability. This result is consistent with the conclusions in $[14,43]$ in the absence of product differentiation.

Third, we discuss the effect of product differentiation on the local stability of the Nash equilibrium. We found that the product differentiation is larger; the Nash equilibrium will become unstable in complementary products reproducing the previous results proposed in the literature (see [15] for the duopoly case and [21] for a differentiated triopoly with linear dynamic system). However, the monotonic relationship between product differentiation and stability is different in alternative products. The threshold for adjusting the speed is the largest and has a certain degree of substitutability (for the fixed adaptive adjustment factor $\beta$ ); if the degree of difference between products is increased, the stability of the Nash equilibrium is difficult to guarantee (note $d$, the case where the right side approaches 0 is established). In the mutual substitution, this result is related to the complementary intertemporal strategy of the product. As a result, reducing the degree of product differentiation may undermine the Nash equilibrium.

Finally, the chaotic behavior of the dynamic system is controlled by time-delay feedback control and the numerical analysis shows that the unstable behavior of the dynamic system can be effectively and quickly controlled, which can quickly restore the stability and order of the market and provide reference for enterprise decision-makers to adjust strategies (in line with the conclusions of [21]).

\section{Data Availability}

The numerical simulations data used to support the findings of this study were supplied by Liuwei Zhao under license and so cannot be made freely available. Requests for access to these data should be made to Liuwei Zhao (e-mail address: 136901672@qq.com).

\section{Conflicts of Interest}

The author declares that there are no conflicts of interest.

\section{Acknowledgments}

This work was supported by the National Natural Science Foundation of China (no. 71974081), the Philosophy \& Social Science Fund for University of Jiangsu (no. 
2019SJA1051), and Jiangsu University of Technology talent introduction project (KYY18539).

\section{References}

[1] A. Cournot, Récherches sur Les Principes Mathématiques de la Théorie des Richesses, Creative Media Partners, Dunod, Paris, 1838 .

[2] J. Bertrand, "Révue de la théorie mathématique de la richesse sociale et des recherches sur les principles mathématiques de la thérie des richesses," Journal des Savants, vol. 48, pp. 499-508, 1883.

[3] R. D. Theocharis, "On the stability of the Cournot solution on the oligopoly problem," The Review of Economic Studies, vol. 27, no. 2, pp. 133-134, 1960.

[4] T. Puu, "On the stability of Cournot equilibrium when the number of competitors increases," Journal of Economic Behavior \& Organization, vol. 66, no. 3-4, pp. 445-456, 2008.

[5] E. Ahmed and H. N. Agiza, "Dynamics of a Cournot game with $n$-competitors," Chaos, Solitons \& Fractals, vol. 9, no. 9, pp. 1513-1517, 1998.

[6] K. Okuguchi, "Adaptive expectations in an oligopoly model," The Review of Economic Studies, vol. 37, no. 2, pp. 233-237, 1970.

[7] W. Wu, Z. Chen, and W. H. Ip, "Complex nonlinear dynamics and controlling chaos in a Cournot duopoly economic model," Nonlinear Analysis: Real World Applications, vol. 11, no. 5, pp. 4363-4377, 2010.

[8] E. Ahmed, A. A. Elsadany, and T. Puu, "On Bertrand duopoly game with differentiated goods," Applied Mathematics and Computation, vol. 251, pp. 169-179, 2015.

[9] G. I. Bischi and A. Naimzada, "Global analysis of a dynamic duopoly game with bounded rationality," in Advances in Dynamic Games and Applications, J. A. Filar, V. Gaitsgory, and K. Mizukami, Eds., vol. 5, Birkhauser, Basel, Switzerland, 2000.

[10] R. Spiegler, Bounded Rationality in Industrial Organization, Oxford University Press, Oxford, UK, 2014.

[11] G. I. Bischi and M. Kopel, "Equilibrium selection in a nonlinear duopoly game with adaptive expectations," Journal of Economic Behavior \& Organization, vol. 46, no. 1, pp. 73-100, 2001.

[12] H. N. Agiza and A. A. Elsadany, "Nonlinear dynamics in the Cournot duopoly game with heterogeneous players," Physica A: Statistical Mechanics and Its Applications, vol. 320, pp. 512-524, 2003.

[13] H. N. Agiza and A. A. Elsadany, "Chaotic dynamics in nonlinear duopoly game with heterogeneous players," Applied Mathematics and Computation, vol. 149, no. 3, pp. 843-860, 2004.

[14] F. Tramontana, "Heterogeneous duopoly with isoelastic demand function," Economic Modelling, vol. 27, no. 1, pp. 350-357, 2010.

[15] L. Fanti and L. Gori, "The dynamics of a differentiated duopoly with quantity competition," Economic Modelling, vol. 29, no. 2, pp. 421-427, 2012.

[16] A. Agliari, L. Gardini, and T. Puu, "Global bifurcations of basins in a triopoly game," International Journal of Bifurcation and Chaos, vol. 12, no. 10, pp. 2175-2207, 2002.

[17] T. Puu, "Complex dynamics with three oligopolists," Chaos, Solitons \& Fractals, vol. 7, no. 12, pp. 2075-2081, 1996.

[18] J. S. C'anovas, "Reducing competitors in cournot-puu oligopoly,” Nonlinear Anal. RWA, vol. 13, pp. 1772-1779, 2012.
[19] A. A. Elsadany, H. N. Agiza, and E. M. Elabbasy, "Complex dynamics and chaos control of heterogeneous quadropoly game," Applied Mathematics and Computation, vol. 219, no. 24, pp. 11110-11118, 2013.

[20] F. Tramontana, A. A. Elsadany, B. Xin, and H. N. Agiza, "Local stability of the Cournot solution with increasing heterogeneous competitors," Nonlinear Analysis: Real World Applications, vol. 26, pp. 150-160, 2015.

[21] J. Andaluz and G. Jarne, "On the dynamics of economic games based on product differentiation," Mathematics and Computers in Simulation, vol. 113, pp. 16-27, 2015.

[22] Z. Sun and J. Ma, "Complexity of triopoly price game in Chinese cold rolled steel market," Nonlinear Dynamics, vol. 67, no. 3, pp. 2001-2008, 2012.

[23] W. Xu and J. Ma, "Study on the dynamic model of a duopoly game with delay in insurance market," WSEAS Transactions on Mathematics, vol. 11, pp. 615-624, 2012.

[24] J. L. Zhang, "Research on delayed complexity based on nonlinear price game of insurance market," WSEAS Transactions on Mathematics, vol. 10, pp. 368-376, 2011.

[25] L. Fanti, L. Gori, C. Mammana, and E. Michetti, "The dynamics of a Bertrand duopoly with differentiated products: synchronization, intermittency and global dynamics," Chaos, Solitons \& Fractals, vol. 52, pp. 73-86, 2013.

[26] L. Zhao and J. Zhang, "Analysis of a duopoly game with heterogeneous players participating in carbon emission trading," Nonlinear Analysis: Modelling and Control, vol. 19, no. 1, pp. 118-131, 2014.

[27] F. Zhang and C. Wang, "Dynamic pricing strategy and coordination in a dual-channel supply chain considering service value," Applied Mathematical Modelling, vol. 54, pp. 722-742, 2018.

[28] Z. Guo, "Complexity and implications on channel conflict under the uncertain impacts of online customer reviews," Nonlinear Dynamics, vol. 96, no. 3, pp. 1971-1987, 2019.

[29] G. I. Bischi, U. Merlone, and E. Pruscini, "Evolutionary dynamics in club goods binary games," Journal of Economic Dynamics and Control, vol. 91, pp. 104-119, 2018.

[30] J. Zhou, W. Zhou, T. Chu, Y.-x. Chang, and M.-j. Huang, "Bifurcation, intermittent chaos and multi-stability in a twostage Cournot game with R\&D spillover and product differentiation," Applied Mathematics and Computation, vol. 341, pp. 358-378, 2019.

[31] W. Zhou and X. X. Wang, "On the stability and multistability in a duopoly game with R\&D spillover and price competition," Discrete Dynamics in Nature and Society, vol. 2019, Article ID 2369898, 20 pages, 2019.

[32] N. Singh and X. Vives, "Price and quantity competition in a differentiated duopoly," The RAND Journal of Economics, vol. 15, no. 4, pp. 546-548, 1984.

[33] C. H. Tremblay and V. J. Tremblay, "The Cournot-Bertrand model and the degree of product differentiation," Economics Letters, vol. 111, no. 3, pp. 233-235, 2011.

[34] C. H. Tremblay, M. J. Tremblay, and V. J. Tremblay, "A general cournot-bertrand model with homogeneous goods," Theoretical Economics Letters, vol. 01, no. 02, pp. 38-40, 2011.

[35] J. Ding, Q. Mei, and H. Yao, "Dynamics and adaptive control of a Duopoly advertising model based on heterogeneous expectations," Nonlinear Dynamics, vol. 67, no. 1, pp. 129$138,2012$.

[36] B. Xin and T. Chen, "On a master-slave Bertrand game model," Economic Modelling, vol. 28, no. 4, pp. 1864-1870, 2011. 
[37] J. Ma and K. Wu, "Complex system and influence of delayed decision on the stability of a triopoly price game model," Nonlinear Dynamics, vol. 73, no. 3, pp. 1741-1751, 2013.

[38] Z. Ding, Q. Li, S. Jiang, and X. Wang, "Dynamics in a Cournot investment game with heterogeneous players," Applied Mathematics and Computation, vol. 256, pp. 939-950, 2015.

[39] X. Liao, Stability Theory and Application of Dynamical Systems, pp. 252-268, National Defence Industry Press, Beijing, China, 2000.

[40] L. Zhao, J. Chang, and J. Du, "Dynamics analysis on competition between manufacturing and remanufacturing in context of government subsidies," Chaos, Solitons \& Fractals, vol. 121, pp. 119-128, 2019.

[41] L. Zhao, J. Du, and Q. Wang, "Nonlinear analysis and chaos control of the complex dynamics of multi-market Cournot game with bounded rationality," Mathematics and Computers in Simulation, vol. 162, pp. 45-57, 2019.

[42] L. Zhao, C. Oduro, and A. Otoo, "Stability and complexity of a novel three-dimensional environmental quality dynamic evolution system," Complexity, vol. 2019, p. 11, 2019.

[43] J. Andaluz, A. A. Elsadany, and G. Jarne, "Nonlinear Cournot and Bertrand-type dynamic triopoly with differentiated products and heterogeneous expectations," Mathematics and Computers in Simulation, vol. 132, pp. 86-99, 2017. 